\title{
Dynamic investigations of various civil engineering structures due to ambient and mining tremors
}

\author{
Krystyna Kuzniar ${ }^{1}$, Tadeusz Tatara ${ }^{2, a}$ \\ ${ }^{1}$ Pedagogical University of Cracow, Institute of Technology, Krakow, Poland \\ ${ }^{2}$ Cracow University of Technology, Faculty of Civil Engineering, Krakow, Poland
}

\begin{abstract}
The first part of the study deals with evaluation of dynamic characteristics of selected typical industrial facilities, such as the extraction steel tower, reinforced concrete tower skips. These structures are located in the coal mine area. The constructions of the test items are varied and complicated, which causes difficulties in the research in situ. In the investigation we used normal and emergency operation of lifting equipment, the effect of wind gusts and rhythmic man swaying. The second part of the study involves the determination of the dynamic characteristics of tailing dam. In this case mining tremors were used as the sources of vibration excitations. By using natural vibration excitation source it was possible to determine the lowest frequency of free vibration of the tailing dam. The third part of the paper focuses on the results of measurements of mine-induced ground vibrations and vibrations of residential buildings of various types. Typical one-family masonry houses as well as 5 and 12 storey reinforced prefabricated buildings were examined. The studies were conducted to determine the transmission of free-field vibrations to the building foundations. According to the significant differences between the simultaneously measured ground and building foundation vibrations, results of experimental tests obtained by means of response spectra are essential for the proper adoption of kinematic loads for dynamic models of these structures. The results of experimental studies were the basis for the verification of dynamic models of investigated structures.
\end{abstract}

\section{Introduction}

Information concerning behavior of structures under different types of loadings is possible to receive using different measurement techniques. It can be non-invasive techniques (e.g. ultrasounds measurements) which are characterized by high accuracy and repeatability. On the other hand there are invasive techniques involving the study of cut specimens from the structure. The approach based on GPS method is more often used in measurements. The PSD (Power Spectral Density), CSD (Cross Spectral Density), Transmittance and Coherence functions were usually applied to determine the natural frequencies of the structures [1].

In structures located in seismic areas or subjected to paraseismic events, dynamic actions are the most dangerous and constitute the main loads for buildings of different type. In those cases measurement methods are based on recordings of induced vibrations or dynamic strains.

The main goal of dynamic measurement is verification of numerical models of structures helpful in analyses of structure behavior. Creation of dynamic model of structure is simple and cheap operation. Unfortunately, very often the resulting calculations of those models are indisputably accepted by the less experienced researchers or designers. Such a situation can lead to getting incorrect results of calculations resulting in the danger of failure of the designed structure. The results of numerical analyzes require verification that can be done experimentally or on the basis of comparative analysis. The results of dynamic measurements are helpful in verification of dynamic models of the analyzed structures. Experimental data from dynamic measurements of buildings is also helpful to determine the transmission of free-field vibrations to building foundations resulting in proper adoption of kinematic loads for dynamic models of these structures. Response spectra created on the basis of recorded vibrations are helpful to solve this problem.

The results of examinations of earthen dams and embankments permitted to establish not only their natural frequencies but also dependence of a critical damping ratio versus frequency of the structures.

Analyzes of vibration records made before and after the track repair permit also to assess the effectiveness of the design of the track due to the level of induced vibrations and their harmfulness for the construction of a residential building, located in the immediate vicinity of the track. The experimental results are the base to establish mathematical relations concerning dependences of the maximum values of the horizontal and vertical components of vibration acceleration measured at

\footnotetext{
$\overline{{ }^{a} \text { Corresponding author: ttatara@pk.edu.pl }}$
} 
ground-level building as functions of the speed of trams as well as the coefficients of the trend line.

Experimental verification (static or dynamic) can be carried out on the basis of results of laboratory tests which use parts of the structure or the entire structure. Often tested models are performed in the scale because of their geometrical parameters or dimensions of hall laboratory. Shaking tables are also used in dynamic tests but such solution is expensive.

The paper presents examples of dynamic testing and the results for selected structures of different types. Tests were conducted in full scale by accredited Laboratory of Testing Distortions and Structural Vibrations located in Institute of Structural Mechanics of Cracow University of Technology. The study focused on showing the possibilities of research in situ dynamic structures for different dynamic excitation. Different types of dynamic forcing are used in the study. They were gusts of wind, rhythmic swaying of people, vibrator Mark - 3 used in the exploration works, natural underground mining tremors and normal and emergency operation of lifting equipment in coal mines.

The examined structures were typical one-family masonry houses as well as 5 and 12 storey RC prefabricated buildings made in large-block technology. The study was also focused on the evaluation of the dynamic characteristics of selected typical, varied and complicated industrial facilities, such as the extraction steel tower, reinforced concrete tower skips located in the coal mine. The researches also dealt with earth dams and earthen embankments located in south part of Poland. An influence of vibrations induced by passages of trams on buildings before and after repair of track were examined to estimate effectiveness of new design solution of track.

\section{Investigated structures}

The study involved a number of selected types of engineering structures of various constructions. These structures can be regarded as typical for industrial structures as well as one- and multi-family buildings. The unusual structure is the biggest in Europe tailing dam whose mission is to protect inhabited areas and the collection of flotation wastes from the production of copper.

\subsection{RC skip tower}

Steel hoist and skip towers are strategic objects for a mine with regard to its operation. Analyzed structure is the RC skip tower located near a pit-coal at Upper Silesian Coal Basin. The tower is supported by four pylons. Its dimensions are $6.7 \times 6.5 \mathrm{~m}$ and the thickness of walls is $30 \mathrm{~cm}$. The columns are founded by means of RC grid. The foundation of the tower consists of RC plate with the thickness of about $1.5 \mathrm{~m}$. The plan dimension of the rectangle plate is $25 \times 34 \mathrm{~m}$ with truncated corners $(2.5 \times 2.5 \mathrm{~m})$ as well as $10 \mathrm{~m}$ diameter opening for a shaft pipe. The foundation is located $7.5 \mathrm{~m}$ below the ground surface. The foundation plate in the basement part is stiffened by the RC grid with the 6- meter high walls.
Total height of the tower from foundation level is more than 100 meters. Figure 1 shows a view and assumed 3D dynamic model of the analyzed structure.
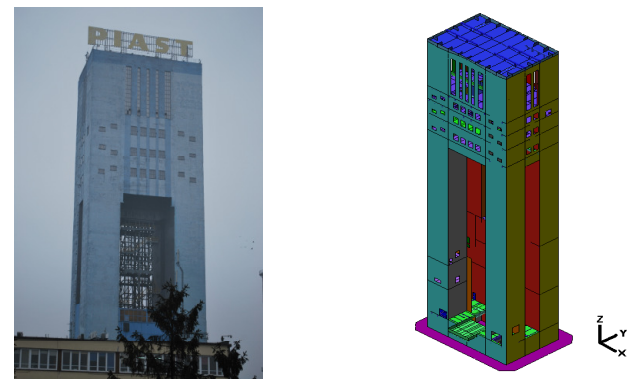

Figure 1. The view of the RC skip tower and its assumed dynamic numerical model

\subsection{Steel hoist tower}

The steel hoist tower is also used in transportation coal from the mine. Investigated tower is two braced structure supported by monolithic RC footings founded on the ground. The length of the tower is 32 meters (spacing of the footings), width of $20 \mathrm{~m}$ (spacing of the footings) and a height of $59 \mathrm{~m}$. Figure 2 shows a view and assumed 3D dynamic model of the analyzed tower, respectively.
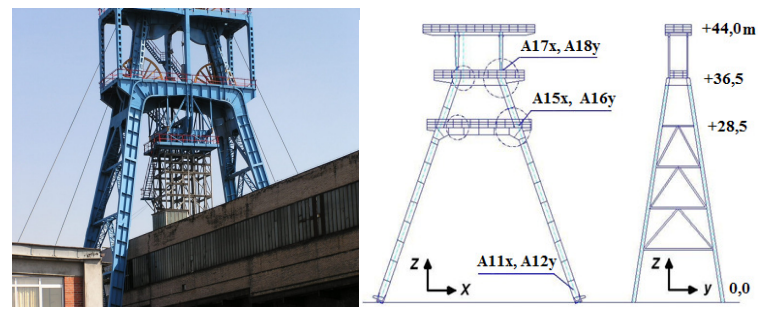

Figure 2. The view and assumed dynamic model of the steel tower

\subsection{Tailing dam}

Building of tailing dam started in seventies of last century in Poland at Legnica - Glogow Copperfield (LGC). Exploitation and simultaneous extension of reservoir have been lasting since 1977 year. Cross - section of structure is irregular and depends on morphology of soil. Realization of embankment begins from building of basic dam that allows the storage of wastes. The reservoir is continuously extended by stage embankment made of dry waste originating from floatation material due to lack of proper conditions to establish building second tailing dam - comp. Figure 3. The wastes are supplied to embankment by a system of pipelines. Every stage has $2,5 \mathrm{~m}$ heights and annual average increment of storage yard height is about $1.3 \mathrm{~m}$. The structure is constantly monitored by set of gauges as piezometers as well as accelerometers. A typical layout of the soil layer and numerical dynamic model of the dam are shown in Figure 4 and 5, respectively. 


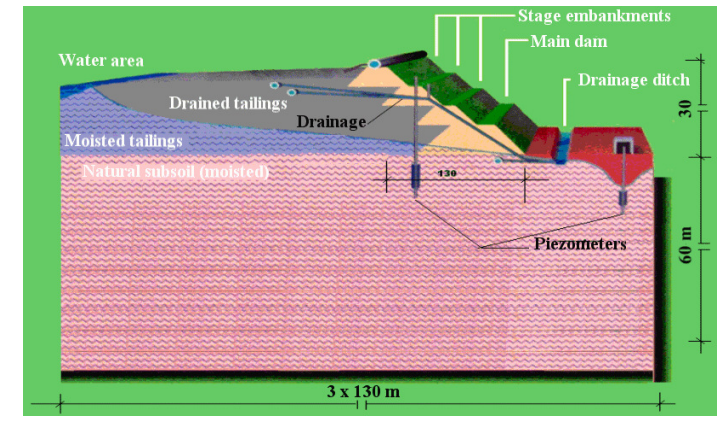

Figure 3. Typical cross-section of the tailing dam

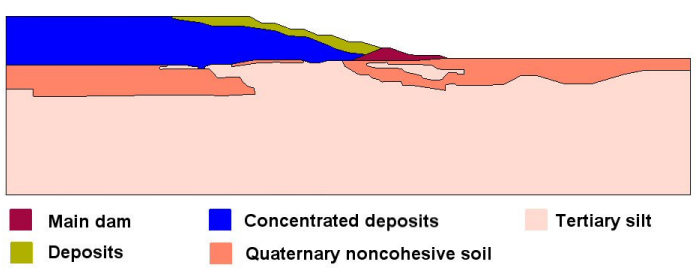

Figure 4. Morphology of the soil layers

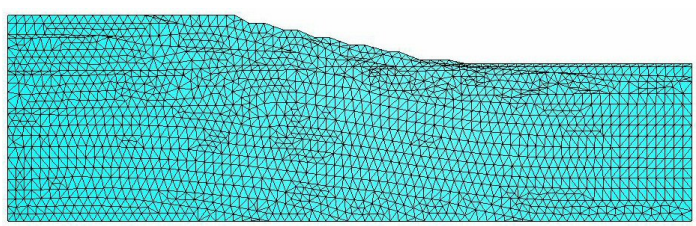

Figure 5. Assumed plane dynamic model of the tailing dam

\subsection{One-family masonry buildings and residential multi-family prefabricated buildings}

Three types of residential buildings of varying constructions and height were the subject of research. The first one is one-family, two-storey, masonry building, plastered, with basement. The building has longitudinaltransverse system of bearing walls. Overall dimensions of building plan, are $9,50 \times 10,00 \mathrm{~m}$, the height above ground $-8,15 \mathrm{~m}$ and depth of foundation $-1,1 \mathrm{~m}$. The subsoil consists of soil near the surface; to $1.5 \mathrm{~m}$ is a layer of sand and gravel, to $4.5 \mathrm{~m}$ compact clay, to $6,8 \mathrm{~m}$ fine and medium quartz sand and from 6.8 to $23 \mathrm{~m}$ compact clay. The plan of the building (denoted as Ak) is shown in Figure 6.

The second structure is five-storey (each storey is $2.8 \mathrm{~m}$ high) one staircase section of the multi-staircases building. This is typical prefabricated apartment fivestorey building with load bearing concrete large-block walls. Each floor and vertical bearing walls of the building are multi-tube wall panels $24 \mathrm{~cm}$ thick prefabricated tube slabs. Vertical bearing elements constitute a mixed transverse - longitudinal system. The building is founded directly on the ground with using concrete strip foundations. The sub-soil consists of soil layer, below the level of 3 meters fine and medium sand, up to 5 meters compact clay with silt, below 5 meters gravel with different granular quartz sand. The plan and sectional elevation of the building (denoted as $3 \mathrm{M}$ ) are shown in Figure 7.

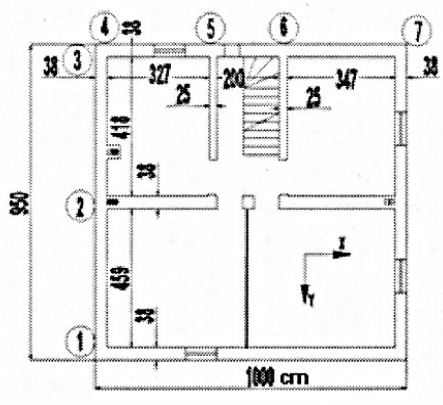

Figure 6. Floor plan of the one-family residential building (Ak)
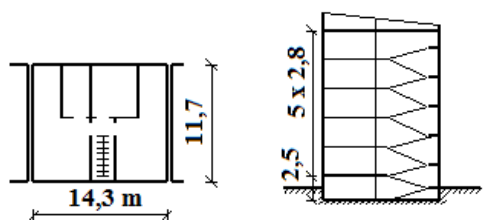

Figure 7. The plan and sectional elevation of the 5 storey building $(3 \mathrm{M})$

The third building (denoted as $\mathrm{Mi}$ ) consists of two separated parts: one and two-staircases. Both parts have fully basement and are founded on strip foundations. The building was erected in the transverse-longitudinal loadbearing wall system (cf. Figure 8). Height of each storey is equal to $2,7 \mathrm{~m}$. Construction of the building has been strengthened by the introduction of additional spans made in the technology of monolithic concrete, adjacent to the gable walls. Strengthening in one-staircase and twostaircase part extend to the seventh and tenth floor, respectively. Mounted strengthening is going across the entire width of the building and is founded on plate foundations. The sub-soil has very similar properties as under the one - family residential building.
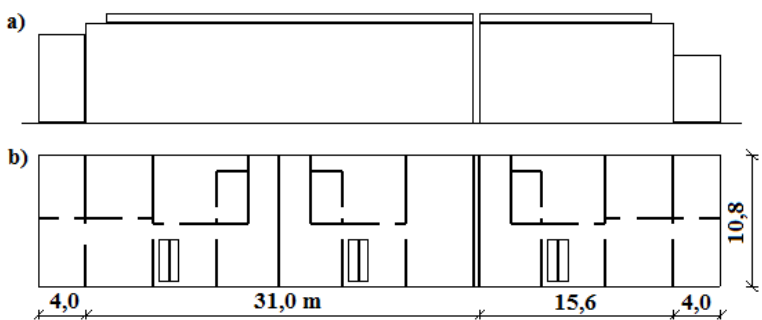

Figure 8. The plan and sectional elevation of the 12 storey building $(\mathrm{Mi})$

\section{Sources of vibrations used in investigations}

Various sources of vibrations were used during the investigations. These sources were controlled by a human or from him independent. Table 1 shows the vibration sources used during the studies. 
Table 1. Vibration sources used in investigations

\begin{tabular}{|l|l|}
\hline \multicolumn{1}{|c|}{$\begin{array}{c}\text { Investigated } \\
\text { structure }\end{array}$} & \multicolumn{1}{c|}{ Source of vibration } \\
\hline Steel hoist tower & Typical work, emergency stopping \\
\hline RC skip tower & Wind gusts, man swaying, typical work \\
\hline Tailing dam & Mining induced vibrations \\
\hline $\begin{array}{l}\text { Earth dam and } \\
\text { embankments }\end{array}$ & Vibrator Mark-3 \\
\hline Dwelling houses & $\begin{array}{l}\text { Mining induced vibrations, paraseismic } \\
\text { vibrations - trams and train passages }\end{array}$ \\
\hline
\end{tabular}

\section{Measuring apparatus, measurement accuracy and methods of processing the results}

Preliminary numerical analysis showed that the natural frequencies of the examined structures are low. As a result, the appropriate instrumentation system and control equipment were chosen, consisting of accelerometers, strain gauges, four-channel amplifier, 16-channel recorder, oscilloscope, and a PC with specialized software to analyze the data records.

The instrumental system consisted of PCB 393B12 accelerometers, digital analyzer LMS Mobile Scadas equipped with an analog low-pass Butterworth filter 0$100 \mathrm{~Hz}$. Linearity deviation PCB sensor signal does not exceed $2.3 \%$. The relative standard uncertainty of the maximum acceleration signal resulting from installation errors, instrumental system and analysis does not exceed $\pm 11.61 \%$.

Measuring devices were installed at chosen levels of the structures. Electro - dynamic strain gauges were fixed at the base of the structures for measuring deformations of the structures, where the maximal strains were expected.

The vibration records obtained at measuring positions have been analysed in frequency domain. Natural frequencies $(f)$ of the investigated structures have been established using Fourier Spectra, acceleration response spectra, power spectral density $P S D(f)$ as well as transfer function $T_{f}(f)$ according to identification theory [1]. Power spectral density describes general frequency structure of random signal. PSD $(f)$ function is performed as a Fourier transform of an autocorrelation function $R_{x}(f)$ of random process $x(t)$ as follows [1]:

$$
\begin{gathered}
P S D_{x}(f)=\int_{-\infty}^{\infty} R_{x}(\tau) e^{-j \omega \tau} d \tau \Rightarrow \\
R_{x}(\tau)=\lim _{T_{S} \rightarrow \infty} \frac{1}{T_{s}} \int_{0}^{T_{S}} x(\tau) x(t+\tau) d \tau
\end{gathered}
$$

where: $\omega=2 \pi f, T_{S}$ - duration of random signal.

Transfer function $T_{f}(f)$ of dynamic system is performed as a relation of cross spectral density $C S D(f)$ function of input $x(t)$ and output $y(t)$ signals to power spectral density $P S D(f)$ of input signal $x(t)[1]$ :

$$
T_{f}(f)=\frac{C S D_{x y}(f)}{P S D_{x}(f)}
$$

Cross spectral density CSD $(f)$ function of two random processes $x(t)$ and $y(t)$ is evaluated as a Fourier transform of cross correlation $R_{x y}(f)$ function of these processes [1]:

$$
\begin{aligned}
& C S D_{x y}(f)=\int_{-\infty}^{\infty} R_{x y}(\tau) e^{-j \omega \tau} d \tau \Rightarrow \\
& R_{x y}(\tau)=\lim _{T_{s} \rightarrow \infty} \frac{1}{T_{s}} \int_{-\infty}^{\infty} x(\tau) y(t+\tau) d \tau
\end{aligned}
$$

Evaluation of natural frequencies of structures was supported by analysis of the transfer and the coherence functions obtained on the basis of the records at the bottom $x(t)$ and the highest $y(t)$ level of object assumed as input and output signals respectively. Coherence function of two signals is defined by [1]:

$$
\gamma_{x y}^{2}(f)=\frac{\left|C S D_{x y}(f)\right|^{2}}{P S D_{x}(f) \cdot P S D_{y}(f)} \leq 1
$$

\section{Exemplary of dynamic investigations of various civil engineering structures}

In this part, we show examples of the results of selected investigated engineering structures focused on determination of their dynamic characteristics and comparison with data from applied numerical models.

\subsection{Steel hoist tower}

Figure 9 presents accelerometers A17x and 18y location at $+36,5$ level of the tower. The records of horizontal acceleration components $\mathrm{x}$ (gauge A17x) caused by typical work of the lifting of carriages with coal and emergency stopping are shown in Figure 10 and 11, respectively.

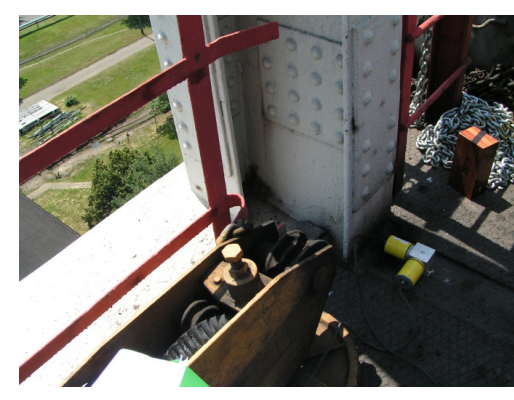

Figure 9. Measurement point at $+36,5 \mathrm{~m}$ level - accelerometers $\mathrm{A} 17 \mathrm{x}$ and A18y - comp. Figure 2

Horizontal components $\mathrm{x}, \mathrm{y}$ of accelerations vibrations recorded in case of typical work as well as emergency stopping of the considered hoist tower were 
the basis to evaluate its resonant frequencies and damping parameters. In order to determine resonant frequencies of the considered tower, recorded signals were analyzed in the frequency domain - comp. part 4 . Exemplary charts of $F F T(f)$ and $P S D(f)$ functions corresponding to acceleration records from Figure 10 are shown in Figure 12 and Figure 13.

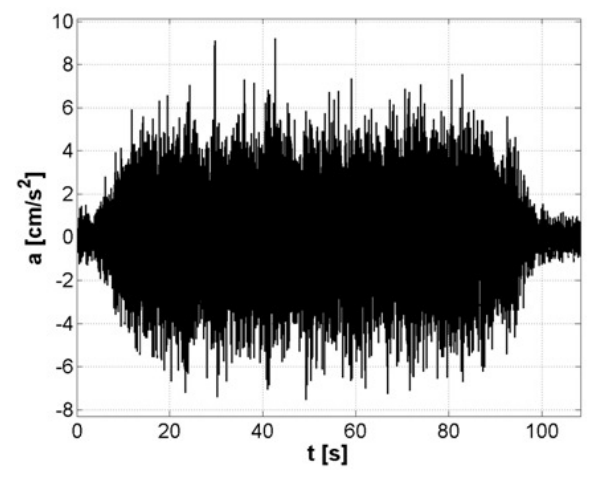

Figure 10. Horizontal component $x$ of acceleration vibration of the steel tower caused by typical work

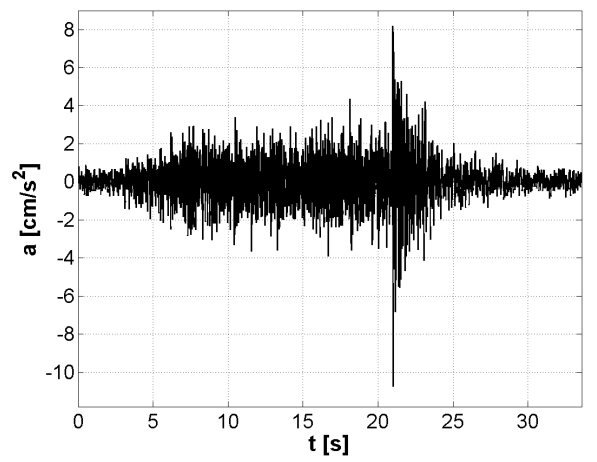

Figure 11. Horizontal component $x$ of acceleration vibration of the steel tower due to emergency stopping

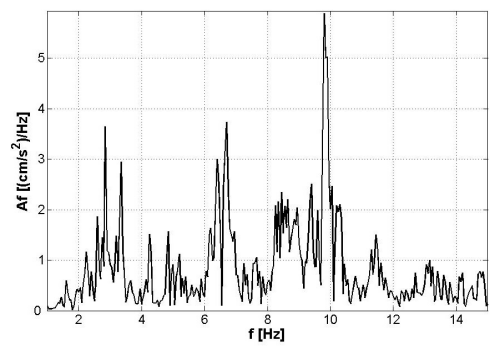

Figure 12. $F F T(f)$ function obtained on the basis of the vibration record from Figure 10

Similarly $F F T(f)$ and $P S D(f)$ functions calculated on the basis of record from Figure 11 are shown in Figures 14 and 15 , respectively. Only frequencies confirmed by analysis of $P S D(f)$ function calculated for all recordings were considered as resonant. Frequency spectrum is dense in both directions $\mathrm{x}$ and $\mathrm{y}$. For instance, the values of resonant frequencies obtained on the basis of curves shown in Figures 10 and 11 were listed in Table 2.

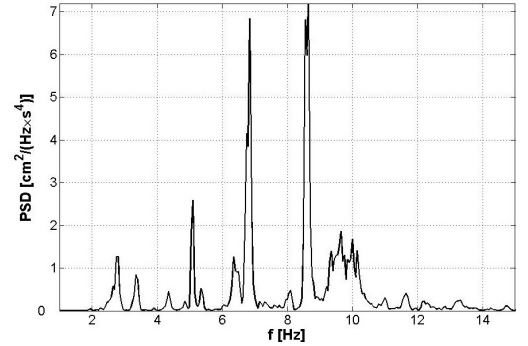

Figure 13. $\operatorname{PS} D(f)$ function obtained on the basis of the vibration record from Figure 10

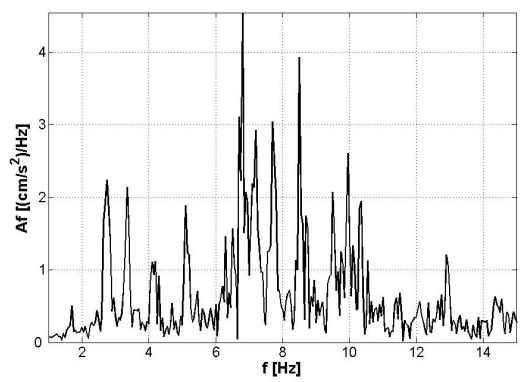

Figure 14. $F F T(f)$ function obtained on the basis of the vibration record from Figure 11

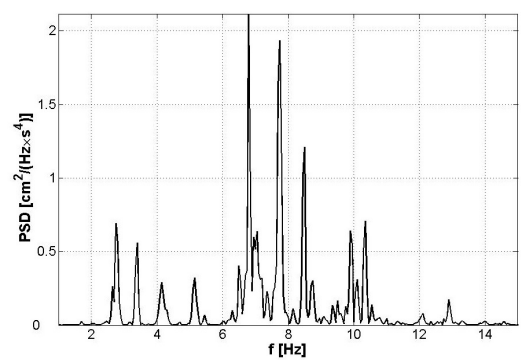

Figure 15. $P S D(f)$ function obtained on the basis of the vibration record from Figure 11

Table 2. Resonant frequencies of investigated steel hoist tower

\begin{tabular}{|c|l|l|}
\hline \multirow{2}{*}{ Direction } & \multicolumn{2}{|c|}{ Source of vibration } \\
\cline { 2 - 3 } & \multicolumn{1}{|c|}{ Typical work } & \multicolumn{1}{|c|}{ Emergency stopping } \\
\hline \multirow{2}{*}{$\mathrm{x}$} & $\begin{array}{l}2,85 ; 3,35 ; 4,25 ; \\
4,85-5,10 ; 6,35-6,85\end{array}$ & $1,7-1,80 ; 2,8 ; 3,35 ;$ \\
\cline { 2 - 3 } $\mathrm{y}$ & 1,$95 ; 2,65-4,30 ; 5,10 ; 6 ; 3,3,35-$ & 2,$75 ; 3,40 ; 4,15 ; 5,15 ; 6,5-$ \\
\hline & 3,$45 ; 4,95-5,1 ; 6,9$ & 6,8 \\
\hline
\end{tabular}

\subsection{Tailing dam}

Underground mining exploitation of mineral resources is the source of underground mining induced rockbursts (MIR) involving seismic vibrations propagating in the soil. Characteristics of surface vibrations caused by rockbursts meaningly differ from earthquakes. According to the matter, the considered embankment of tailing dam is equipped with measurement system for recording of seismic events influencing the structure. The system consists of three measurements cross - sections denoted as IIW, VIIIW and XVIE - comp. Figure 16. Two 
measuring posts are installed in each cross-section. These measuring posts are shifted about $52 \mathrm{~m}$ to each other. Each post is equipped with three accelerometers measuring acceleration of vibrations in three perpendicular directions (two horizontal $\mathrm{x}, \mathrm{y}$ and vertical $\mathrm{z})$.

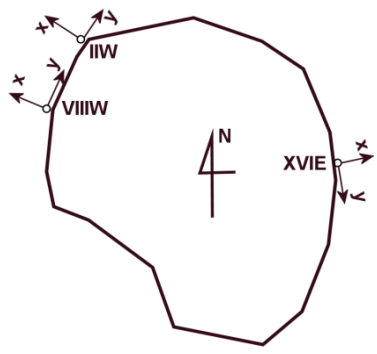

Figure 16. Schematic overview of the tailing dam with measurement points

Exemplary horizontal component $\mathrm{x}$ of vibration records measured at the bottom and crest of the tailing dam at the cross - section VIIIW are plotted in Figures $17 \mathrm{a}$ and $17 \mathrm{~b}$ respectively. a)

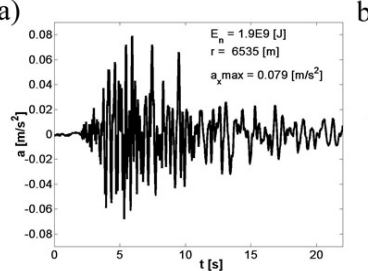

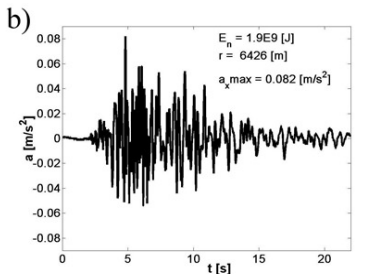

Figure 17. Horizontal component $x$ of ground accelerations recorded at the bottom (a) and at the crest (b) of the tailing dam

Plots of PSD $(f)$ function, Transfer and Coherence Functions performed on the basis of vibration records measured simultaneously at the bottom and crest levels (comp. Figure 17) are listed in Figure 18 and Figure $19 \mathrm{a}, \mathrm{b}$, respectively. We assumed that the frequencies corresponding to values of coherence function bigger than 0,85 may be treated as resonant frequencies. Ranges of resonant frequencies of the tailing dam in direction $\mathrm{x}$ determined on the basis of the $P S D(f)$, module of the $T(f)$ and Coherence Functions as well as natural frequencies calculated using applied model of the structure are listed in Table 3.

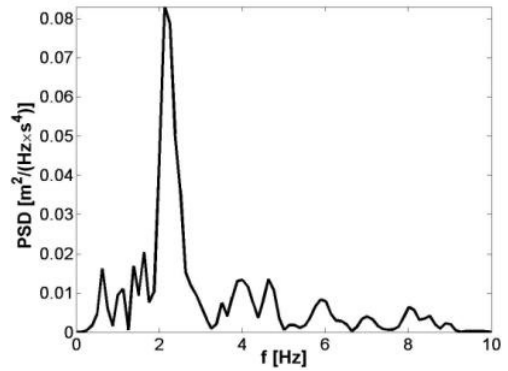

Figure 18. $P S D(f)$ function corresponding to the record in Figure $17 \mathrm{~b}$

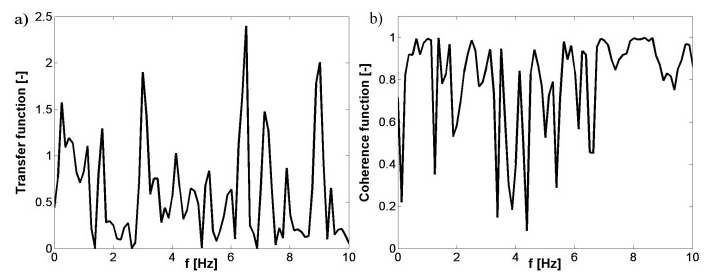

Figure 19. Plots of functions: a) transfer [-], b) coherence [-] corresponding to vibrations recorded at the bottom and crest of the tailing dam

Table 3. Comparison of natural frequencies $f, \mathrm{~Hz}$ of the tailing dam in $\mathrm{x}$ direction

\begin{tabular}{|c|c|c|}
\hline \multirow{2}{*}{ No. } & \multicolumn{2}{|c|}{ Frequencies, Hz obtained from: } \\
\cline { 2 - 3 } & measurement & calculation \\
\hline 1 & 0,88 & 0,9 \\
\hline 2 & - & 1,30 \\
\hline 3 & - & - \\
\hline 4 & 1,75 & 1,73 \\
\hline 5 & - & 1,89 \\
\hline 6 & - & 2,11 \\
\hline 7 & - & 2,19 \\
\hline 8 & 2,25 & 2,34 \\
\hline 9 & - & - \\
\hline 10 & $2,75-2,88$ & 2,72 \\
\hline
\end{tabular}

Comparing calculated and measured frequencies we admit that fundamental frequency in transverse direction $\mathrm{x}$ is low and is equal about $0,9 \mathrm{~Hz}$. Response spectra in Figure 20 confirm results listed in Table 3 referring to $x$ direction.

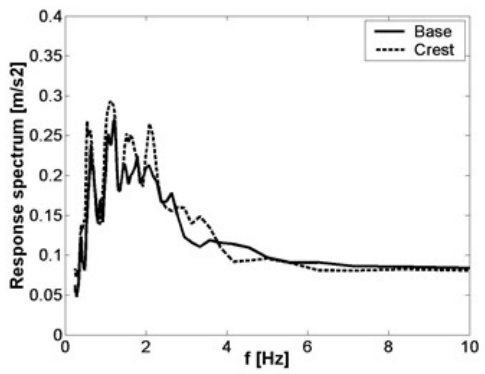

Figure 20. Acceleration response spectra corresponding to the records in Figure 17

The previously made researches confirmed that the most adequate model of the tailing dam is the one considering effective stresses and saturation [2]. The calculated natural frequencies are confirmed by results from measurements. The differences do not exceed $6 \%$. The model may be used in future calculations referring to dynamic behavior of the system due to seismic loading.

\subsection{RC skip tower}

Figure 21 presents location of accelerometers at the top level of the tower. The dynamic tests the RC skip tower 
with a height of $100 \mathrm{~m}$ were performed using different ways of excitation - cf. Figure 22 and Table 4.

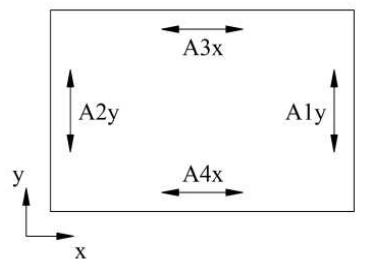

Figure 21. Sketch layout of the accelerometers at the level $80,01 \mathrm{~m}$ above ground surface

In Figure 22 there are plotted exemplary $\operatorname{PSD}(f)$ functions of analyzed records of the skip tower due to different excitation of its vibrations. The results of experimental studies allowed verification of the calculation results of natural frequencies using the 3D FEM model of the skip tower - comp. Figure 1.
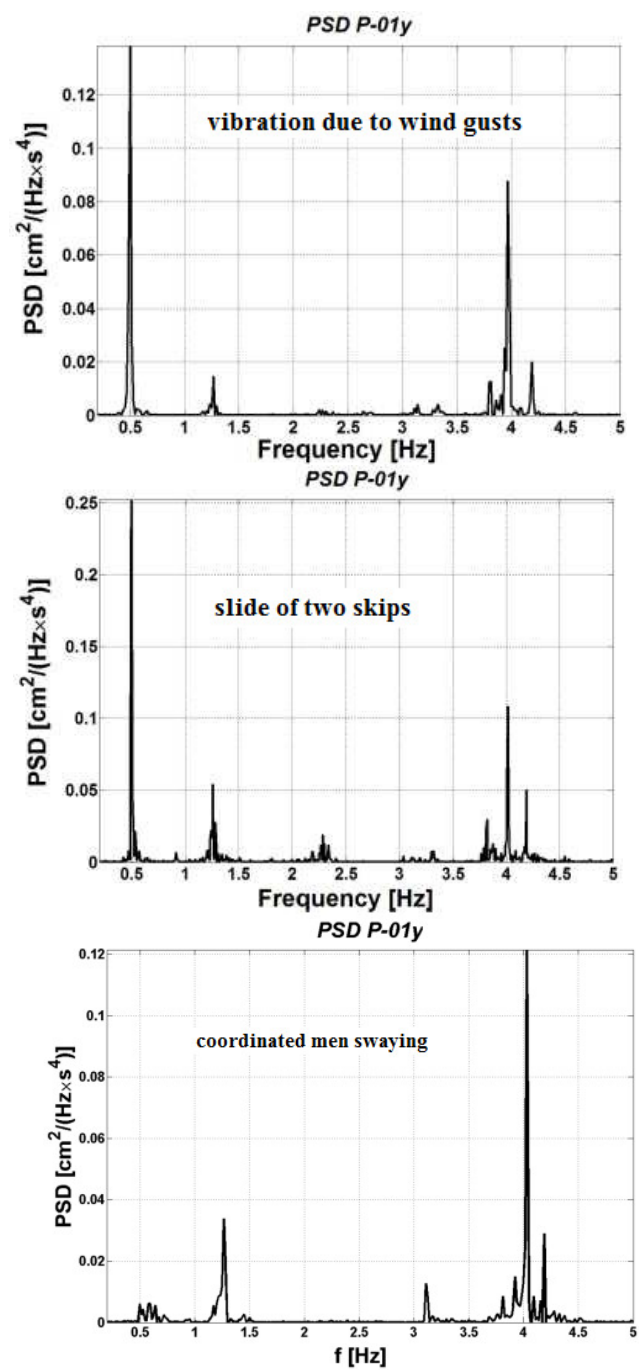

Figure 22. $P S D(f)$ functions of the horizontal component y of tower vibration due to applied excitations at the level $80,01 \mathrm{~m}$ above ground surface
These results are very similar (cf. Table 4). The first fundamental frequency of vibration is accurately imitated in the model and corresponds to the natural frequency of vibrations in the direction of the lower stiffness of structure (direction y). This frequency is important for the determination of the wind load. Very good agreement was also obtained for the second natural frequency, for which the difference between the measured and calculated values does not exceed $10 \%$. The third natural frequency corresponding to torsional mode shape was confirmed but the difference in the quantitative convergence is about $20 \%$.

Table 4. Comparison of the measurement results with those obtained using theoretical model of the RC skip tower

\begin{tabular}{|c|c|c|c|c|}
\hline $\begin{array}{c}\text { No of } \\
\text { frequency }\end{array}$ & $\begin{array}{c}\text { Measured } \\
\text { value of } \\
\text { frequency, } \\
\mathbf{H z}\end{array}$ & $\begin{array}{c}\text { Mode } \\
\text { shape }\end{array}$ & $\begin{array}{c}\text { Calculated } \\
\text { value of } \\
\text { frequency, } \\
\text { Hz }\end{array}$ & $\begin{array}{c}\text { Difference } \\
\text { between the } \\
\text { calculated } \\
\text { and } \\
\text { measured } \\
\text { values of } \\
\text { the }\end{array}$ \\
\hline $\mathbf{1}$ & $0,50-0,51$ & $\begin{array}{c}\text { Flexural } \\
\text { in y dir. }\end{array}$ & 0,5 & $0-2$ \\
\hline $\mathbf{f}$ & $0,65-0,67$ & $\begin{array}{c}\text { Flexural } \\
\text { in x dir. }\end{array}$ & 0,72 & $6,9-9,7$ \\
\hline $\mathbf{3}$ & $1,23-1,27$ & Torsional \\
\hline $\mathbf{4}$ & 3,96 & $\begin{array}{c}\text { Flexural } \\
\text { in y dir. }\end{array}$ & 3,06 & 29,4 \\
\hline $\mathbf{5}$ & 4,18 & $\begin{array}{c}\text { Flexural } \\
\text { in x dir. }\end{array}$ & 4,90 & $19,6-19,9$ \\
\hline
\end{tabular}

\subsection{Residential buildings}

Existing tram sub-grade is also subjected to rebuilding and maintenance works. The proposed and introduced structural changes require recognition. New foundation of the tramway track was applied in one of the streets in Krakow during rebuilding sub-grade. The new sub-grade was designed and executed as so called "ecological" one. The main aim of measurements is evaluation of effectiveness of the applied new foundation of the tramtrack. Analyses of vibrations records of building (masonry, two storeys high with basement) due to tram passages before and after repair of the sub-grade were compared to evaluate effectiveness of dynamic design solution of tramway substructure. Comparison of the distribution of maximal values of the most intensive component of acceleration vibrations of the building due to tram passages of different type are shown in Figures 23 and 24. The level of vibration amplitudes induced by tram passages of $105 \mathrm{~N}$ type has decreased in band of $0-$ $100 \mathrm{~Hz}$ - comp. Figure 23. Tram passages of GT6+B4 type excite a higher level of amplitudes of $\mathrm{x}, \mathrm{y}, \mathrm{z}$ components of building vibrations at ground level for frequencies $\mathrm{f}>40 \mathrm{~Hz}-$ comp. Figure 24 . 


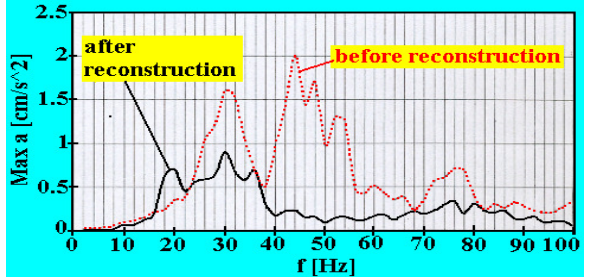

Figure 23. Distribution of maximal values of horizontal component $\mathrm{x}$ of acceleration vibrations of the building at ground level due to tram of $105 \mathrm{~N}$ type passage

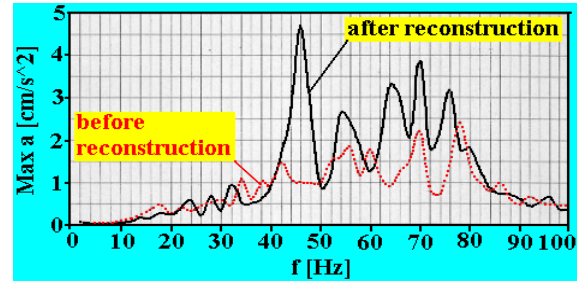

Figure 24. Distribution of maximal values of horizontal component $\mathrm{x}$ of acceleration vibrations of the building at ground level due to tram of GT6+B4 type passage

Dynamic measurements of the buildings were also focused on determining how the free - field vibrations transmit to the foundations of buildings of different types. Simultaneously recorded ground and building foundation vibration accelerations are used to determine dynamic soil - structure interaction. The phenomenon of dynamic interaction was studied for three types of buildings listed in part 2.4 and treated as representative building structures in the Legnica-Glogow Copperfield (LGC) in Poland. The surface vibrations were caused by mining rockbursts induced by underground extraction of copper ore. The phenomenon of interaction was studied by comparing the average acceleration response spectra calculated on the basis of the recorded surface vibrations from hundreds of mining rockbursts in the analyzed seismic area. Response spectra obtained on the basis of horizontal components $\mathrm{x}$, $\mathrm{y}$ of free-ground vibrations $\left(\mathrm{S}_{\mathrm{ag}}\right)$ and on the basis of buildings foundation $\left(\mathrm{S}_{\mathrm{af}}\right)$ are shown in Figure 25. The presented average spectra were calculated using the package response spectra $S_{\text {axg }}$ and $S_{\text {ayg }}\left(\right.$ as $\left.S_{a g}\right)$ and $S_{\text {axf }}$ and $S_{\text {ayf }}\left(\right.$ as $S_{a f}$ ) separately for three analyzed buildings. The former results of dynamic investigations of the buildings were the base to apply value of average fraction of critical damping equal $3 \%$ for calculation of response spectra [3].

a)

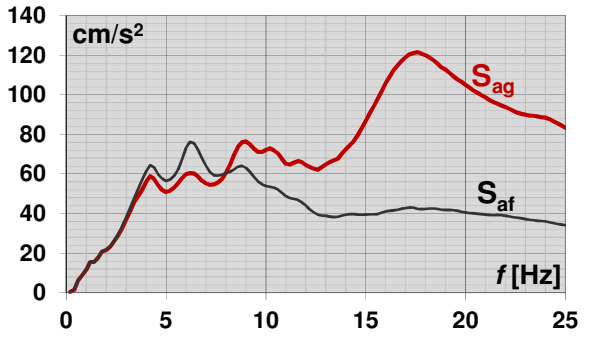

b)

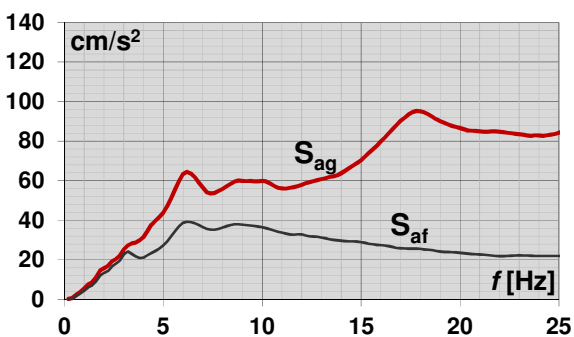

c)

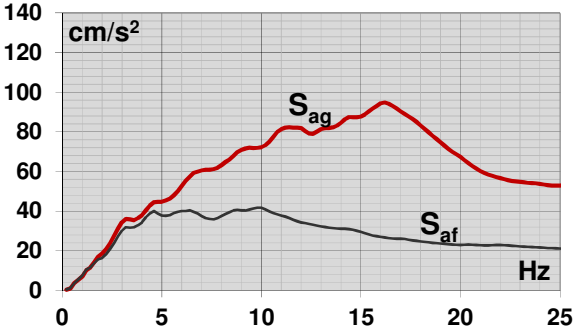

Figure 25. Average response spectra $S_{a g}$ and $S_{a f}$ : a) the $A k$ station and the Ak building foundation, b) the $3 \mathrm{M}$ station and the $3 \mathrm{M}$ building foundation, c) the $\mathrm{Mi}$ station and the $\mathrm{Mi}$ building foundation.

\section{Conclusions and final remarks}

The study refers to selected dynamic investigations of selected engineering structures realized in situ. The results of the study were the basis for determining the dynamic characteristics and experimental verification of dynamic models adopted for these structures. Different ways to excite the vibrations of the structures were used. The test results are also helpful in determining how vibrations from the free-field transmit to the building foundations as well as for choosing proper kinematic excitation for applied numerical models of the structures. Besides, the results of dynamic tests were the basis of a dynamic assessment of the dynamic effectiveness of the method used for the repair of the tramway. The results can be the basis for future design work and choose the type of trams, which runs nearby buildings, cause low vibration.

\section{References}

1. H. Bachmann et al., Vibration Problems in Structures. Practical Guidelines, Birkhäuser Verlag AG, (1994)

2. T. Tatara, P. Kuboń P, Dynamic properties of tailing dam under mining induced seismic events, Proc. 9th Intern. Conf. on Struct. Dyn., EURODYN'2014, Porto, Portugal, 30 June - 2 July (2014).

3. R. Ciesielski et. al., Damping of vibration in precast buildings with bearing concrete walls, Arch. Civ. Eng. 41, 3 (1995). 